\title{
Assessment of community's knowledge, attitude and practice about onchocerciasis and community directed treatment with Ivermectin in Quara District, north western Ethiopia
}

Fitsum Weldegebreal ${ }^{1 *}$, Girmay Medhin ${ }^{2}$, Zemichael Weldegebriel ${ }^{3}$ and Mengistu Legesse ${ }^{2}$

\begin{abstract}
Background: The African Program for Onchocerciasis Control (APOC) has been working with ultimate goal of reducing the public health and socio-economic problems associated with onchocerciasis within a period of 12-15 years. Although dedicated community engagement is crucial for the success of the program, there is little/no information on the levels of community's knowledge, attitude and practice about onchocerciasis as well as about the ongoing control program in Ethiopia. In this study, we have assessed the level of knowledge, attitude and practice of Quara district residents about onchocerciasis and the current control strategies in the area.

Methods: This community-based cross-sectional study was conducted between October 2012 and January 2013 in Quara District, Amhara Regional State, North West of Ethiopia. The study participants were recruited from randomly selected kebeles (small administrative units) of the study area and were interviewed about onchocerciasis and about community directed treatment with ivermectin (CDTI) using structured questionnaire. The collected data were double entered into a data entry file using EpiData software, V.3.1. The data were transferred to SPSS soft-ware V.16 and analyzed according to the different variables.
\end{abstract}

Results: Out of 418 respondents, 401 (95.9\%) of the respondents have heard about onchocerciasis (locally known as 'wara') and $11.2 \%$ said that they knew about the etiology of the disease, which was named as filarial worm. However, 356 (88.8\%) had at least one misconception about the causative agent of onchocerciasis. More than half (69.4\%) knew that the transmission of the disease is related to black fly biting. Overall, 93.3\% participants believed that onchocerciasis is preventable, of whom $49.5 \%$ indicated use of drug as the means of preventing the disease. Majority (95.5\%) of the participants perceived CDTI as very useful program.

Conclusion: Although onchocerciasis is endemic disease in the study area, large proportion of the community had conspicuous misconceptions in all issues about its causation, transmission and preventive methods. This could affect the success of the CDTIP in the present study area. Therefore we recommend increasing the awareness about onchocerciasis in the area through community-based campaigns during drug distribution with especial focuses on females and age group less than 35 years".

\footnotetext{
*Correspondence: fwmlab2000@gmail.com

'Department of Medical laboratory Science, Haramaya University, College of

Health and Medical Science, Harar, Ethiopia

Full list of author information is available at the end of the article
} 


\section{Background}

Onchocerciasis is a disease caused by Onchocerca volvulus (O.volvulus). The disease is characterized by causing skin lesions with severe itching, a serious eye lesion and blindness known as river blindness. The disease is a major problem among rural communities living in close proximity to rivers in Sub-Saharan African countries, Latin and Central America [1]. It spreads by the biting of black flies belonging to the genus Simulium which breed in fast flowing rivers.

The ultimate goal of the African Program for Onchocerciasis Control (APOC) is to reduce the public health and socio-economic problems of onchocerciasis within a period of 12-15 years using the strategy of yearly communitydirected treatment with ivermectin (CDTI) in endemic areas. Population-based chemotherapy program using ivermectin is highly effective, feasible and offers a different approach to the control of onchocerciasis $[2,3]$. Ivermectin, when taken annually, has the ability to bring about sustained reduction in skin and eye microfilariae to very low levels with reduction in morbidity $[4,5]$ and transmission [6,7].

A complete national survey (1997-2004) in Ethiopia indicated that onchocerciasis was Endemic in nine regions, with 7.3 million people at risk and more than 3 million already infected. The prevalence of onchocerciasis in Ethiopia ranges from 6.9\% in the Quara District of Northwest Ethiopia to $85.3 \%$ in Teppi, South western Ethiopia [8].

Community is the heart of the APOC strategy for controlling onchocerciasis. Community ownership of the distribution program has been a major innovation for mass treatment, and has been a corner stone to the success of CDTI. However, the full participation of the community could be largely affected by several factors including low level of community's awareness about the disease, community's attitudes towards the program, system of drug distribution and the motivation of community drug distributors (CDDs) [9]. A community-based free distribution of ivermectin was first launched in Sheka Zone, Southwestern Ethiopia in the year 2001 and then, in the rest of affected regions it was launched phase by phase [10]. CDTI program was introduced to Quara District in 2003 by WHO/APOC in partnership with Federal Ministry of Health (FMOH), the Carter Centre, the local administration and the communities. All eligible members of the community in the District have been treated with ivermectin in campaign once a year. Pregnant women, less than one week of lactating mothers, seriously ill individuals and under five children are not eligible. Except individuals mentioned above, any individual living in the selected area is eligible for the CDTIP [11].

Ignorance and wrong beliefs about the disease can lead to negligence in prevention and control measures and it causes accepting inappropriate treatment. Involvement of individuals and communities is an important component of onchocerciasis control activities. To attain community participation and design socially/locally acceptable control strategies, health program planners and implementers must be familiar with people's knowledge and attitude in relation to onchocerciasis [12]. The successful use of ivermectin at national, regional, zonal, District and kebeles requires a broad public health program designed to ensure appropriate distribution, monitoring, community education, and record keeping. There is paucity of information as few studies have been carried out to understand these issues. Therefore, a study aimed at assessing factors affecting the sustainability of the program has great importance to generate information on the awareness, challenges and obstacles faced during ivermectin distribution, and design appropriate strategy to improve the outcomes. The finding of this study will serve as an input for the Quara District Health Office while designing monitoring and evaluation of the on-going onchocericiasis control program. The information obtained from the study provides a basis for understanding how best to sustain community control and to achieve success in the control of onchocerciasis as a public health and socioeconomic problem in the study area. However, the knowledge of the communities about onchocerciasis and their attitude towards the CDTIP has not been studied in the present study area. Therefore, the aim of this study was to investigate people's knowledge and beliefs about onchocerciasis and their attitudes towards the CDTIP in Quara area, North Western Ethiopia.

\section{Methods and materials}

\section{Description of the study area and population}

Between October 2012 and January 2013, a communitybased cross sectional survey was conducted in Quara District, North western Ethiopia, which is about 1041 kilometers North of Addis Ababa and 324 kilometers North-west of Gondar town. The District has a total area of 858,580 square kilometers and it shares geographical boarder with Metema District in the North, Benshangul Regional State in the South, North Sudan in the West, Alefa District in East and Awi zone in South West. There are three major ethnic groups in the District (i.e. Aguw, Amhara and Gumuz) and there are also minorities who come from Tigray, Oromiya and the Southern Nations Nationalities and Peoples Region (SNNPR). Based on the 2007 national housing and population census [13], the District has 19 kebeles (small administrative unit) with a total population of 93,629 , consisting of 49,750 men and 43,879 women. The District has 20, 806 households with an estimated density of 4.50 person per square kilometer [13]. CDTI program was introduced to Quara District in 2003 by WHO/APOC in partnership with $\mathrm{FMOH}$, the 
Carter Centre, the local administration and the communities with $100 \%$ geographic coverage [11].

Out of the 19 kebeles of the District 17 kebeles were occupied by the Amhara ethnic group and the other 2 kebeles were occupied by the Aguw and Gumuz ethnic groups. In the District, there were 5 health centers and 28 health posts, giving routine services for the population. Onchocerciasis is one of the major public health problems in the District [11] with the prevalence of $6.9 \%[8]$.

\section{Sample size estimation and data collection}

There was no previous information on the level of community's knowledge, attitude and practice about onchocerciasis in the present study area. Hence, it was hypothesized that at least $50 \%$ of adult residents of the target area (i.e. 18 years of age or above) would have a good level of knowledge about the disease (i.e. they will score above the mean value within a given sample). Hence, sample size was estimated taking this as the starting point with 95\% confidence and 5\% degree of accuracy. Since the source population is very mobile, sample size was increased by $10 \%$ to compensate for non-respondents resulting in the final sample size of 422 . The participants were eligible if they were a member of the selected kebele, age 18 and above years, apparently healthy and willing to volunteer to participate in the study.

Two out of the 17 kebeles occupied by Amhara ethnic group were randomly selected, while each kebele of the Aguw and Gumuz ethnic groups were purposely included. Based on the number of people aged 18 years and above in each kebele, the pre-estimated sample size of 422 was proportionally distributed. Ivermectin treatment registration book of each kebele was used as the sampling frame. Study participants were recruited using systematic random sampling. In case the selected individual was absent in the first and second visit, the next individual on the list whose age was 18 years or above was included. Structured questionnaires were prepared in English based on information from available literatures $(9 ; 12 ; 14 ; 15)$ and the questionnaires were translated into Amharic and pre-tested for clarity and cultural acceptability in the district. The participants were interviewed in their local languages by trained data collectors (health extension workers) who speak the local languages. Each interview was made by house-to-house visit. Information on the socio-demo-graphic characteristics of the participants was also included in the questionnaires.

\section{Ethical consideration}

The study protocol was approved by the Ethical Clearance Committee of Aklilu Lemma Institute of Pathobiology (ALIPB), Addis Ababa University. Permission was obtained from Quara District Health Office and from the four selected kebeles administrators. Participants were informed about the objective of the study and they were assured the confidentiality of the data to be maintained. Informed verbal consent was obtained from all participants prior to data collection.

\section{Data analysis}

The collected data were double entered into a data entry file using EpiData software, V.3.1. The data were transferred to SPSS soft-ware V.16 and analyzed according to the different variables. Pearson chi-square was used to evaluate the statistical significant of bivariate association of selected covariate. Odds ratio with $95 \%$ CI generated using logistic regression were used to describe the strength of association between the selected study variables (i.e. outcome and independent variables) before and after controlling for possible confoundering variables. Bivariate and multivariable logistic regression analysis was performed to explore independent variables that were predictors of overall knowledge (causative agents, sign/symptoms, mode of transmission, treatment and preventive methods of onchocerciasis), attitude and practice of the people on onchocerciasis and CDTIP. The correct answer was coded as 1 and wrong answer was coded as 0 . To generate the overall knowledge, attitude and practice score of all correct responses were added. Respondents whose knowledge, attitude and practice scores equal and above the mean were considered as having 'good knowledge, attitude and practice' while those below the mean were considered as having 'poor knowledge, attitude and practice'. The criterion for significance was set at $\mathrm{P}<0.05$ based on a two-sided test.

\section{Results}

\section{Socio-demographic characteristics of the study} participants

From the random community sample of 422, we were able to attain response rate of $99.1 \%$ and female respondents constituted of $37.3 \%$. The age of the respondents ranged from 18-87 years, with mean age of 35.2 and SD of 11.7 years. The majority were in the age range of 25 to 49 years, and was belonged to Amhara ethnic group, farmers and followers of Orthodox Christianity (Table 1).

\section{Knowledge, attitude and practice of the community about onchocerciasis}

The most important identifying perceptions of the community which hinder the uptake of preventive and treatment services in the district were: they were at field (farming) during the campaign day; CDDs were not coming to their house to provide them with the treatment, they believed that freely given medications are useless for health and they feared side effects of the drug. The level of knowledge, attitude and practice of 
Table 1 Socio-demographic characteristics of 418 study participants recruited from the community, Quara District, 2013

\begin{tabular}{|c|c|c|c|}
\hline Characteristics & Number (\%) & Characteristics & Number (\%) \\
\hline Kebele & & Religion & \\
\hline Yikaho & $63(15.1)$ & Orthodox Christian & $337(80.6)$ \\
\hline Mahdid & $62(14.8)$ & Muslims & $81(19.4)$ \\
\hline Bambaho & $126(30.1)$ & Educational level & \\
\hline Dubaba & $167(40)$ & Illiterate & $248(59.3)$ \\
\hline Gender & & Primary (grades 1-8) & $142(34.0)$ \\
\hline Male & $262(62.7)$ & Secondary and above & $28(6.7)$ \\
\hline Female & 156(37.3) & Occupation & \\
\hline Age (years) & & Farmer & $349(83.5)$ \\
\hline $18-24$ & $67(16.0)$ & Others & $69(16.5)$ \\
\hline $25-49$ & $303(72.5)$ & Family size & \\
\hline $50-64$ & $35(8.4)$ & $1-4$ & $230(55.0)$ \\
\hline $65+$ & $13(3.1)$ & $5+$ & $188(45.0)$ \\
\hline \multicolumn{4}{|l|}{ Ethnicity } \\
\hline Amhara & 293(70.1) & & \\
\hline Agew & $63(15.1)$ & & \\
\hline Gumuz & $62(14.8)$ & & \\
\hline \multicolumn{4}{|l|}{ Marital status } \\
\hline Unmarried & $48(11.5)$ & & \\
\hline Married & $365(85.2)$ & & \\
\hline Others & $14(3.3)$ & & \\
\hline
\end{tabular}

respondents is summarized in Tables 2, 3 and 4. Out of 418 respondents, $95.9 \%$ have heard about onchocerciasis (locally known as 'wara') and $11.2 \%$ said that they knew about the etiology of the disease, which was named as filarial worm. On the other hand, $88.8 \%$ had at least one misconception about the causative agent of onchocerciasis including black fly biting (58.1\%), poor personal hygiene, and living in poor environmental sanitation, eating contaminated food, and witchcraft. More than half of the respondents (58.6\%) mentioned that onchocerciasis can be transmitted and most of them (69.4\%) knew that the transmission of the disease is related to black fly biting. The remaining suggested contact with a person who has the disease, mosquito bite, sharing cloths and through breathing as mode of transmission. Majority (78.1\%) of the participants mentioned itching as a symptom of the disease, while $42.6 \%$ and $26.7 \%$ mentioned skin change and edema as a symptom of onchocerciasis, respectively. Three hundred seventy seven (94.0\%) knew that onchocerciasis is treatable disease.

Among the total respondents, 386 (96.3\%) said that onchocerciasis is a serious disease and 374 (93.3\%) believed that onchocerciasis is preventable disease. Among the total respondents, 370 (98.1\%) knew that the disease
Table 2 Knowledge of community respondents $(n=418)$ about onchocerciasis, Quara District, 2013

\begin{tabular}{|c|c|c|c|}
\hline $\begin{array}{l}\text { Indicative questions on } \\
\text { knowledge }\end{array}$ & Response categ & ories & Number (\%) \\
\hline \multirow{2}{*}{$\begin{array}{l}\text { Have you ever heard about } \\
\text { the disease called } \\
\text { onchocerciasis }\end{array}$} & \multicolumn{2}{|l|}{ Yes } & 401(95.9) \\
\hline & \multicolumn{2}{|l|}{ No } & $17(4.1)$ \\
\hline \multirow{9}{*}{$\begin{array}{l}\text { Causative agent } \\
\text { of onchocerciasis }\end{array}$} & \multicolumn{2}{|l|}{ Filarial worm } & $45(11.2)$ \\
\hline & \multicolumn{2}{|l|}{ Black fly } & 233(58.1) \\
\hline & \multicolumn{2}{|l|}{ Mosquito } & $14(3.5)$ \\
\hline & \multicolumn{2}{|c|}{$\begin{array}{l}\text { Living in poor } \\
\text { environmental sanitation }\end{array}$} & $59(14.7)$ \\
\hline & \multicolumn{2}{|c|}{ Poor personal hygiene } & $33(8.2)$ \\
\hline & \multicolumn{2}{|l|}{ Witchcraft } & $2(0.5)$ \\
\hline & \multicolumn{2}{|c|}{ Eating contaminated food } & $1(0.2)$ \\
\hline & \multicolumn{2}{|c|}{ Being not vaccinated } & $9(2.2)$ \\
\hline & \multicolumn{2}{|l|}{ Do not know } & $5(1.2)$ \\
\hline \multirow{3}{*}{$\begin{array}{l}\text { Oncho transmits from person } \\
\text { to person }\end{array}$} & \multicolumn{2}{|l|}{ Yes } & 235(58.6) \\
\hline & \multicolumn{2}{|l|}{ No } & 120(29.9) \\
\hline & \multicolumn{2}{|l|}{ I do not known } & $46(11.5)$ \\
\hline \multirow{6}{*}{$\begin{array}{l}\text { The mode of transmissions } \\
\text { of the disease }\end{array}$} & \multicolumn{2}{|l|}{ Black fly bite } & 163(69.4) \\
\hline & \multicolumn{2}{|c|}{$\begin{array}{l}\text { Contact with infected } \\
\text { person }\end{array}$} & $40(17.0)$ \\
\hline & \multicolumn{2}{|l|}{ Mosquito bite } & 19(8.1) \\
\hline & \multicolumn{2}{|l|}{ Through breath } & $1(0.4)$ \\
\hline & \multicolumn{2}{|l|}{ Sharing clothes } & $9(3.8)$ \\
\hline & \multicolumn{2}{|l|}{ I do not know } & $3(1.3)$ \\
\hline \multirow{3}{*}{$\begin{array}{l}\text { The signs and symptoms of } \\
\text { the disease }\end{array}$} & Itching & Yes & $313(78.1)$ \\
\hline & Edema & Yes & 107(26.7) \\
\hline & Skin change & Yes & $171(42.6)$ \\
\hline \multirow{3}{*}{$\begin{array}{l}\text { Do you think oncho is } \\
\text { preventable disease }\end{array}$} & \multicolumn{2}{|l|}{ Yes } & 374(93.3) \\
\hline & \multicolumn{2}{|l|}{ No } & $11(2.7)$ \\
\hline & \multicolumn{2}{|l|}{ I do not know } & $16(4.0)$ \\
\hline
\end{tabular}

is treated with modern medicine and from these respondents 327 (88.4\%) knew the name of the drug used to treat the disease i.e. ivermectin/mectizan. Regarding preventive methods, $50.8 \%$ suggested avoiding river bathing, 49.5\% mentioned taking drug, and $40.9 \%$ mentioned wearing protective cloths and $37.7 \%$ mentioned use of bed net. About $31.4 \%$ of the respondents reported that they/their families had got the disease (Table 3).

From the total respondents, 190 (47.4\%), 182 (45.4\%) and $62(15.5 \%)$ had good level of knowledge, attitude and practice towards onchocerciasis, respectively (Figure 1).

\section{Community's knowledge, attitude and practice about CDTI}

All of the respondents knew that CDTIP has been initiated in their kebeles. Among the respondents, 350 (83.7\%) knew that CDDs distribute the drug and 398 (95.2\%) knew 
Table 3 Attitude and practice of community respondents ( $n=418$ ) towards onchocerciasis, Quara District, 2013

\begin{tabular}{|c|c|c|}
\hline $\begin{array}{l}\text { Indicative questions on } \\
\text { attitude and practice }\end{array}$ & Response categories & Number (\%) \\
\hline \multirow{3}{*}{$\begin{array}{l}\text { Have you/your families ever } \\
\text { been sick from onchocerciasis }\end{array}$} & Yes & $126(31.4)$ \\
\hline & No & 267(66.6) \\
\hline & I do not remember & $8(2.0)$ \\
\hline \multirow{3}{*}{$\begin{array}{l}\text { Is onchocerciasis a serious } \\
\text { disease }\end{array}$} & Yes & $386(96.3)$ \\
\hline & No & $10(2.5)$ \\
\hline & I don't know & $5(1.2)$ \\
\hline \multirow{3}{*}{$\begin{array}{l}\text { Do you think onchocerciasis } \\
\text { need treatment }\end{array}$} & Yes & $377(94.0)$ \\
\hline & No & $12(3.0)$ \\
\hline & I do not know & $12(3.0)$ \\
\hline \multirow[t]{2}{*}{ Type of treatment used } & Modern & $370(98.1)$ \\
\hline & Traditional & $7(1.9)$ \\
\hline \multirow{2}{*}{$\begin{array}{l}\text { If Modern, which drug is } \\
\text { needed to treat the disease }\end{array}$} & Ivermectin/Mectizan & $327(88.4)$ \\
\hline & Albendazole & $43(11.6)$ \\
\hline \multirow{6}{*}{$\begin{array}{l}\text { What do you do to prevent } \\
\text { onchocerciasis }\end{array}$} & Avoiding river bathing & $204(54.5)$ \\
\hline & $\begin{array}{l}\text { Wearing protective } \\
\text { clothes }\end{array}$ & 153(40.9) \\
\hline & Taking drug & $185(49.5)$ \\
\hline & Using bed net & $141(37.7)$ \\
\hline & $\begin{array}{l}\text { Environmental } \\
\text { sanitation }\end{array}$ & $93(24.9)$ \\
\hline & Personal hygiene & $53(14.2)$ \\
\hline \multirow{2}{*}{$\begin{array}{l}\text { If your answer for the above } \\
\text { question is Wearing } \\
\text { protective clothes, in what } \\
\text { way is used }\end{array}$} & $\begin{array}{l}\text { In the lower extremities } \\
\text { (below the knees) }\end{array}$ & 124(81.0) \\
\hline & $\begin{array}{l}\text { Around head \& } \\
\text { shoulders }\end{array}$ & $29(19.0)$ \\
\hline
\end{tabular}

that CDDs distribute the drug during week end or holidays. Among the respondents, 266 (63.6\%) mentioned that the drug was distributed properly and 315 (75.4\%) knew that the drug has other useful effect, of whom $285(90.5 \%)$ mentioned that the drug used to treat intestinal parasitic infections. Majority of the respondents (83.7\%) mentioned that the drug was distributed house to house. Among the respondents, 87 (20.8\%) knew that the treatment period is decided by the community, but others knew that the treatment period is decided by the District health Office (48.6\%), CDDs (16\%), HEWs (12.2\%) and community leaders (2.2\%).

Among the respondents, 409 (97.8\%) knew their responsibility on the program and 395 (95.5\%) perceived CDTI as very useful program, but $16(3.8 \%)$ perceived the program as partially useful. For sustainability of this program, 195 (46.7\%) recommended continuous drug supply, while 180 (43.1\%) recommended incentive for CDDs. The majority $(79.7 \%)$ responded that all eligible family members took the drug annually, whereas 85
Table 4 Attitude and practice of community respondents about CDTI, Quara District, 2013

\begin{tabular}{|c|c|c|}
\hline $\begin{array}{l}\text { Indicative questions on } \\
\text { attitude and practice }\end{array}$ & Response & $\begin{array}{l}\text { Number } \\
(\%)\end{array}$ \\
\hline \multirow{4}{*}{$\begin{array}{l}\text { How do you/your family } \\
\text { perceive CDTI }\end{array}$} & Very useful & $399(95.5)$ \\
\hline & Partially useful & $16(3.8)$ \\
\hline & Not useful & $2(0.5)$ \\
\hline & I do not know & $1(0.2)$ \\
\hline \multirow[t]{2}{*}{$\begin{array}{l}\text { What is your contribution in } \\
\text { the CDTI }\end{array}$} & $\begin{array}{l}\text { Taking the drug } \\
\text { continuously }\end{array}$ & 409(97.8) \\
\hline & I do not know & $9(2.2)$ \\
\hline \multirow{3}{*}{$\begin{array}{l}\text { Do you think the program } \\
\text { on controlling Onchocerciasis } \\
\text { is effective }\end{array}$} & Yes & 399(95.5) \\
\hline & No & $7(1.7)$ \\
\hline & I do not know & $12(2.9)$ \\
\hline \multirow{4}{*}{$\begin{array}{l}\text { What do you recommend to } \\
\text { continue the program }\end{array}$} & Drug supply & 195(46.7) \\
\hline & Transport & $42(10.0)$ \\
\hline & Incentive for CDDs & $180(43.1)$ \\
\hline & No comment & $1(0.2)$ \\
\hline \multirow{2}{*}{$\begin{array}{l}\text { Have all eligible family } \\
\text { members received ivermectin }\end{array}$} & Yes & $333(79.7)$ \\
\hline & No & $85(20.3)$ \\
\hline \multirow{3}{*}{$\begin{array}{l}\text { If your answer is no, who } \\
\text { missed the treatment }\end{array}$} & wife & $44(51.8)$ \\
\hline & Husband & $34(40.0)$ \\
\hline & Children & $7(8.2)$ \\
\hline \multirow{2}{*}{$\begin{array}{l}\text { How many times did he/she } \\
\text { or you miss the treatment }\end{array}$} & One year & $71(83.5)$ \\
\hline & Two years & $14(16.5)$ \\
\hline \multirow{3}{*}{$\begin{array}{l}\text { Why did he /she or you } \\
\text { missed treatment }\end{array}$} & Pregnancy & $37(43.5)$ \\
\hline & Health problem & $41(48.3)$ \\
\hline & $\begin{array}{l}\text { Not present during } \\
\text { drug distribution }\end{array}$ & $7(8.2)$ \\
\hline \multirow{2}{*}{$\begin{array}{l}\text { Do you know who interrupted } \\
\text { the treat treatment in the village }\end{array}$} & Yes & $126(30.1)$ \\
\hline & I do not know & 292(69.9) \\
\hline \multirow{2}{*}{$\begin{array}{l}\text { If your answer is yes, What was } \\
\text { the reason to interrupt the } \\
\text { treatment }\end{array}$} & Side effect of drug & $68(50.7)$ \\
\hline & $\begin{array}{l}\text { Lack of good case } \\
\text { management in } \\
\text { side effect }\end{array}$ & $66(49.3)$ \\
\hline $\begin{array}{l}\text { When did you received your } \\
\text { last }\end{array}$ & last year & $397(95.0)$ \\
\hline Treatment & Before two years & $21(5.0)$ \\
\hline \multirow{3}{*}{$\begin{array}{l}\text { Did the drug have any side } \\
\text { effects }\end{array}$} & Yes & 163(39.0) \\
\hline & No & $248(59.3)$ \\
\hline & I don't know & $7(1.7)$ \\
\hline
\end{tabular}

(20.3\%) responded that family members missed at least one round of the drug due to health problems, pregnancy and absence during drug distribution. To facilitate the late memory to the reaction of the drug, the respondents were asked ${ }^{\#}$ when did they receive the last treatment ${ }^{\$}, 397$ (95\%) of the respondents responded last year (Table 4). 


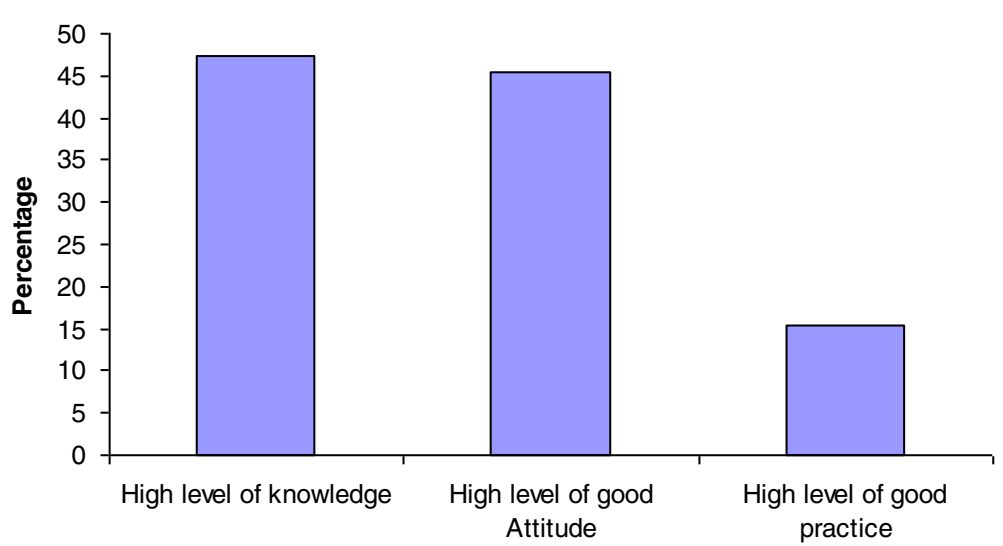

Figure 1 Level of community's knowledge, good attitude and good practice of towards onchocerciasis, Quara District, 2013. Each percentage represents fraction of total respondents who have scored above mean score within each category of the three outcomes.

From the total of 422 respondents $171(40.9 \%)$ had good level of knowledge, 191(45.7\%) had positive attitude and $96(23.0 \%)$ and had good practice towards CDTIP (Figure 2).

\section{Results from Bivariate analysis}

In bivariate analysis, ethnicity was the only factor associated with community's knowledge, attitude and practice towards onchocerciasis: Participants who belong to Amhara ethnic group were about 4 times more likely to have good level of knowledge compared to participants from Agewu ethnic group (crude $\mathrm{OR}=4.44, \mathrm{P}<0.001,95 \% \mathrm{CI}=2.11$, 9.35), and about 9 times more likely to have good level of knowledge compared to participants from Gumuz ethnic group (crude OR $=9.17, \mathrm{P}<0.001,95 \% \mathrm{CI}=4.18,20.00$ ). With regard attitude towards the disease, participants from Amhara ethnic group were 4 times more likely to have good level of positive attitude compared to participants from Agewu ethnic group (crude OR $=4.44, \mathrm{P}<0.001,95 \%$ $\mathrm{CI}=2.14,9.26$ ), and 27 times more likely to have good level of positive attitude compared to participants from the Gumuz ethnic group (crude $\mathrm{OR}=27.03, \mathrm{P}<0.001$, 95\% CI $=9.71,76.92$ ). Similarly, being Amhara ethnic group was 3 times more likely to have good level of positive practice compared to that of Agewu ethnic group (crude $\mathrm{OR}=2.68, \mathrm{P}=0.031,95 \% \mathrm{CI}=1.12,8.40$ ), and 7 times more likely to have good level of positive practice compared to Gumuz ethnic group (crude OR $=6.76$, $\mathrm{P}=0.005,95 \% \mathrm{CI}=1.78,25.64$ ) (Table 5).

Regarding practice towards CDTIP, male respondents were about 2 times more likely to have good practice compared to female respondents (crude $\mathrm{OR}=1.77, \mathrm{P}=0.033$, $95 \% \mathrm{CI}=1.05,2.99)$. On the other hand, none of the examined factors were significantly associated with high level of knowledge or high level of positive attitude towards the disease or the program (Table 6).

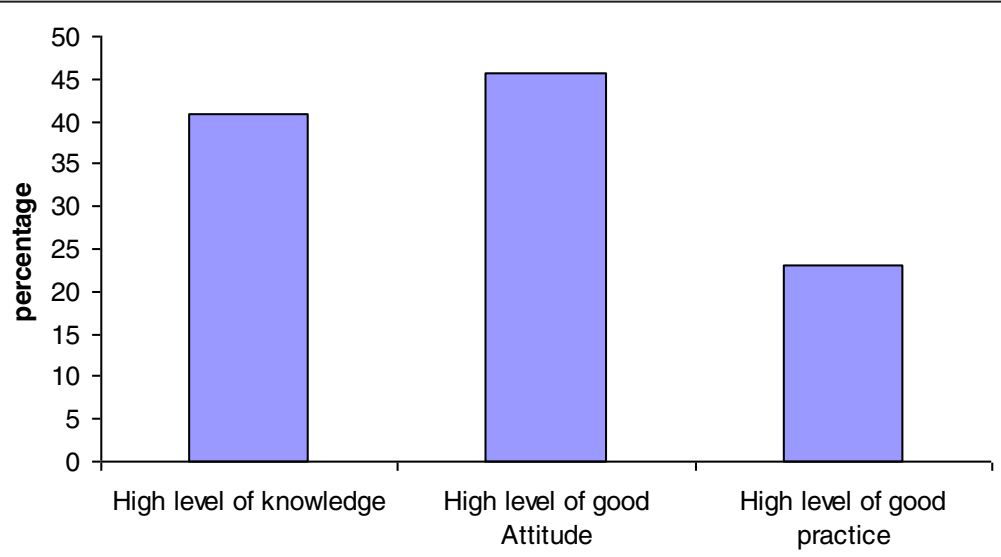

Figure 2 Level of knowledge, good attitude and good practice of community about CDTI, Quara District, 2013. Each percentage represented fraction of total respondents who have scored above the mean score within each category of the three outcomes. 
Table 5 Results of bivariate analysis about onchocerciasis

\begin{tabular}{llll}
\hline Variable & & Crude odds ratio, 95\% Cl & p-value \\
\hline Ethnicity & & & \\
\hline Knowledge & Agew & 1 & $<\mathbf{0 . 0 0 1}$ \\
& Amhara & $\mathbf{4 . 4 4 4}(2.114,9.346)$ & \\
& Gumuz & 1 & $<\mathbf{0 . 0 0 1}$ \\
& Amhara & $\mathbf{9 . 1 7 4}(4.184,20.00)$ & \\
Attitude & Agew & 1 & $<\mathbf{0 . 0 0 1}$ \\
& Amhara & $\mathbf{4 . 4 4 4}(2.141,9.259)$ & \\
& Gumuz & 1 & $<\mathbf{0 . 0 0 1}$ \\
& Amhara & $\mathbf{2 7 . 0 2 7}(9.709,76.923)$ & \\
Practice & Agew & 1 & $\mathbf{0 . 0 3 1}$ \\
& Amhara & $\mathbf{2 . 6 8 1}(1.115,8.403)$ & $\mathbf{0 . 0 0 5}$ \\
& Gumuz & 1 & \\
\hline
\end{tabular}

\section{Discussion}

Majorities of the study participants were familiar with onchocerciasis; this is probably due to the endemicity of the disease in the study area. In the area, the disease is called as 'wara' which means 'itching skin disease'. However, many authorities believe that low knowledge and practice of the peasants of rural Africa predispose them to infection [14]. In this study, from 418 subjects, only 45 (11.2\%) knew about the etiology (causative agent) of the disease and the majority held at least one misconception about the cause of onchocerciasis which is consistent with the findings of other studies $(9 ; 12 ; 17)$. On the other hand, the majority of the respondents associated the causative agent of the disease with the bite of black flies, which is almost comparable to the finding of study conducted in Bebeka, Southwest Ethiopia [12]. Similarly, in this study, majority of the participants held at least one misconception about mode of transmission of onchocerciasis which is consistent with the findings of the study conducted in Bebeka, Southwest Ethiopia [12].

Majority of the study subjects believed that onchocerciasis is a serious disease. This finding is also in agreement with the findings of the studies conducted in Bebeka Southwest Ethiopia [12] and Sequa area, Southwest Ethiopia [15]. However, majority of the study participants had good knowledge about sign and symptoms of the disease; this is probably due to the endemicity of the

Table 6 Rresult of Bivariate Analysis of Community Respondents about CDTI

\begin{tabular}{llll}
\hline Variables & & Crude odds ratio, $\mathbf{9 5 \%} \mathbf{C l}$ & p-value \\
\hline \multirow{2}{*}{ Practice } & Sex & & \\
& Female & 1 & 0.033 \\
& Male & $\mathbf{1 . 7 6 7}(1.046,2.985)$ & \\
\hline
\end{tabular}

disease in the study area and the finding is consistent with the findings of the study conducted in Sequa area, Southwest Ethiopia [15].

Generally, in this study, majority of the study participants had poor level knowledge of onchocerciasis (i.e. only $45.5 \%$ of the participants had good level of knowledge). This finding is also consistent with the findings of the study conducted in Sequa area, Southwest Ethiopia [15]. Similarly, majority of the study subjects had poor attitude and practice about onchocerciasis (i.e. only $45.4 \%$ and $14.8 \%$ study subjects had good attitude and good practice on onchocerciasis, respectively) which is probably due to shortage of health education at the community level and the CDDs may not be properly trained about onchocerciasis due to negligence of health extension workers to supervise the CDDs in delivering health education, and/or excluding the community interventions for onchocerciasis in the health extension package.

Community ownership of the distribution program has been a major innovation for mass treatment, and has been a corner stone to the success of CDTI. The full participation of the community could be largely affected by the drug reaction compared to endemicity of the disease [16]. In this study, the full participation of the community could be largely affected by the drug reaction, CDDs were not coming to their house to provide them with the treatment, they believed that freely given medications are useless for health and they feared side effects of the drug. This observation is consistent with the studies conducted in Okpuje, an endemic community in Edo State, Nigeria [17]. In this study, almost all of the participants knew ivermectin is very important for significant reduction in morbidity and take the drug annually properly. This observation is consistent with the studies conducted in a hyper-endemic community of Edo State, Nigeria [9], and Ethiopia [15] and in Imo State, Nigeria [18]. However, a few individuals interrupted the treatment due to fear of drug related adverse reactions which is similar to the findings of studies conducted in an endemic area of Guatemala [19], in Okpuje, an endemic community in Edo State, Nigeria [17], in the hyper-endemic community of Edo State, Nigeria [9] and in Sequa area, Southwest Ethiopia [15].

In addition to this, they knew that the drug has other useful effect including treating intestinal parasitic infections. The finding is consistent with the findings of the study conducted in North East Nigeria [20] and Sequa area, Southwest Ethiopia [15].

In this study, majority of the study participants mentioned that the coverage of ivermectin distribution was $100 \%$, which is necessary for significant and persistent regression in morbidity. This coverage is better in magnitude compared to the findings of the study conducted in Sequa area, Southwest Ethiopia study [15]; this is probably 
due to the long period (ten years) distribution of the drug in the present study area. The limitations of this study were: the study was not supported by qualitative methods like focus group discussions and epidemiological studies. In spite of this limitation, this study provides an important information regarding knowledge, attitude and practice of community towards onchocerciasis and CDTI chemotherapy for onchocerciasis control, identifying perceptions of the community which hinder the uptake of preventive and treatment services in the district, and base line information for the Quara District Health Office for planning, monitoring and evaluation of the on-going onchocericiasis control.

\section{Conclusion}

In conclusion, though many people in the study communities are familiar with onchocerciasis, most of them lack information on the correct causative agent, mode of transmission and prevention of onchocerciasis with conspicuous misconceptions in all issues. This could affect the success of the CDTIP in the present study area. Hence, this study revealed the need for increasing the awareness about onchocerciasis in the area through communitybased campaigns during drug distribution with especial focus on females and age group less than 35 years is very important for the effectiveness of the program. This will important to improve acceptance and support of the CDTI. Development of health education materials should focus on causative agent, mode of transmission, and prevention of onchocerciasis information in order to ensure better understanding of individuals about the disease.

\section{Competing interests}

The authors declare that they have no competing interests.

\section{Authors' contributions}

FW designed the study, participated in data collection, analysis,

interpretation, and write-up, drafted the manuscript and critically revised the manuscript. ML participated in study design, critically revised the manuscript. GM participated in study design, and critically revised the manuscript. ZW participated in data collection and analysis and interpretation. All authors read and approved the final manuscript.

\section{Acknowledgements}

We are grateful to the study participants, Quara Districts Health office, Health extension workers and Communities Leaders. The study was financially supported by the Addis Ababa University, Aklilu Lemma Institute of Pathobiology.

\section{Author details}

${ }^{1}$ Department of Medical laboratory Science, Haramaya University, College of Health and Medical Science, Harar, Ethiopia. ${ }^{2}$ Aklilu Lemma Institute of Pathobiology, Addis Ababa University, Addis Ababa, Ethiopia. ${ }^{3}$ Metema Hospital, Gendwuha, North Gondar, Amhara Region, Ethiopia.

Received: 12 September 2013 Accepted: 28 February 2014 Published: 10 March 2014

\section{References}

1. WHO: Onchocerciasis and its control. Report of a WHO Expert Committee on Onchocerciasis control. Geneva: WHO; 1995. Technical report series no. 852
2. Tielsch JM, Beeche A: Impact of ivermectin on illness and disability associated with onchocerciasis. Trop Med Intern Health 2004, 9:A45-A56.

3. Taylor HR, Green BM: The World status of ivermectin in the: treatment of human Onchocerciasis. Am J Trop Med Hyg 1989, 41:460-66.

4. WHO: Tropical disease Research progress 1995-96, Thirteenth Progress Report. UNDPNorld Bank/WHO/TDR/97; 1997.

5. Abiose A: Onchocercal eye disease and the impact of mectizan treatment. Ann Trop Med Parasitol 1998, 92:511-522.

6. Cupp EW, Ochoa JO, Collins RC, Cupp M, Gonzales-Peralta C, Castro J, Zea-Flores G: The effects of repetitive community-wide ivermectin treatment on transmission of Onchocerca volvulus in Guatemala. Am J Trop Med Hyg 1992, 47:170-180.

7. Remme H: Effect of ivermectin on elimination of onchocerciasis transmission. TDR news. 2002, 67:4.

8. Rasheed MU: Onchocerciasis in Different Regions of Ethiopia. The Inter $J$ Par Dis 2007, 1:1

9. Wagbatsoma VA, Aisien MSO: Knowledge,attitude and perceptions of onchocerciasis in a hyper-endemic community of Edo State, Nigeria. Afr.J. Clin. Exper. Microbiol 2004, 5:236-237.

10. Taticheff S, Alamrew D, Gebre T: Onchocerciasis. Epidemiology and ecology of health and diseases in Ethiopia 2006, 11:591-608.

11. Quara District Health Office (QDHO): Health management information system report. Gelegu, North west Ethiopia; 2011/2012.

12. Yirga D, Woldemichael K, Wondafrash M, Kassahun W, Deribe K: Knowledge and Belief about Cause and Prevention of Onchocerciasis in Bebeka, Southwest Ethiopia. Ethiop J Health Sci 2008, 18:66-68.

13. CSA: Central Stastical Authority report of Ethiopia. Addis Ababa, Ethiopia; 2008.

14. Ukoli FMA: Prevention and control of parasitic diseases in tropical Africa: The main issues. Ibadan: University Press; 1992.

15. Yesuf A: Assessment of KAP of CDTI of onchocerciasis among the communities around Sega area, southwestern Ethiopia. Addis Ababa, Ethiopia: MSC. Thesis, Addis Ababa University; 2006.

16. Akogun OB, Akogun MK, Audu Z: Ciologommunity perceived benefits of ivermectin treatment in North Eastern Nigeria. Soc Sci and Med 2000, 50:1451-61.

17. Wogu MD, Okaka CE: Knowledge, Attitude and Perception of Onchocerciasis and Ivermectin treatment by the people in Okpuje, Edo State, Nigeria. Intern J Biomed Health Sci 2008, 4:122-23.

18. Abanobi OC: Community based mass distribution of ivermectin for the control of human onchocerciasis in Ehime communities. Imo State, Nigeria: Eye and Vision; 2000:1-56.

19. Richards F, Klein RE, Gonzales-Peralta C, Flores RZ, Flores GZ, Ramirez JC: Knowledge, attitude and perceptions (KAP) of onchocerciasis: a survey among residents in an endemic area in Guatemala targeted for mass chemotherapy with ivermectin. Soc Sci Med 1991, 32:275-281.

20. Ogbuokiri JE, Ozumba BC, Okonkwo PO: Ivermectin levels in human breast milk. Eur J Pharmacolog. 1993, 4:389-90.

doi:10.1186/1756-3305-7-98

Cite this article as: Weldegebreal et al:: Assessment of community's knowledge, attitude and practice about onchocerciasis and community directed treatment with Ivermectin in Quara District, north western Ethiopia. Parasites \& Vectors 2014 7:98.

\section{Submit your next manuscript to BioMed Central and take full advantage of:}

- Convenient online submission

- Thorough peer review

- No space constraints or color figure charges

- Immediate publication on acceptance

- Inclusion in PubMed, CAS, Scopus and Google Scholar

- Research which is freely available for redistribution 